Supporting Information for:

DOI: $10.1021 /$ acs.est.5b04529

\title{
Multispecies Biofilms Transform Selenium Oxyanions into \\ Elemental Selenium Particles: Studies Using Combined Synchrotron X-ray Fluorescence Imaging and Scanning Transmission X-ray Microscopy
}

Soo In Yang, ${ }^{\dagger}$ Graham N. George, ${ }^{\dagger}$ John R. Lawrence, ${ }^{\star}$ Susan G. W. Kaminskyj, ${ }^{\S}$

James J. Dynes, ${ }^{\Perp}$ Barry Lai, ${ }^{\perp}$ and Ingrid J. Pickering* ${ }^{\dagger}$

${ }^{\dagger}$ Department of Geological Sciences, and ${ }^{\S}$ Department of Biology, University of Saskatchewan, Saskatoon, Saskatchewan S7N 5E2, Canada

*National Hydrology Research Centre, Environment Canada, Saskatoon, Saskatchewan S7N 3H5, Canada

'Canadian Light Source, Saskatoon, Saskatchewan S7N 2V3, Canada

${ }^{\perp}$ Advanced Photon Source, Argonne National Laboratory, Argonne, Illinois 60439, United States

(3 pages; 1 table and 2 figures)

*Corresponding Author:

Phone: 1 (306) 966-5706; email: ingrid.pickering@usask.ca 
Table S1. Maximum and average areal elemental concentrations in multispecies biofilms shown in Figure 1 and $2 *$

\begin{tabular}{|c|c|c|c|c|c|c|c|c|c|c|c|c|}
\hline \multirow[t]{2}{*}{ Treatment } & \multirow{2}{*}{$\begin{array}{c}\text { Added Se } \\
\text { concentration } \\
(\mathrm{mM})\end{array}$} & \multicolumn{10}{|c|}{ Maximum elemental concentration $\left(\mu \mathrm{g} / \mathrm{cm}^{2}\right)$} & \multirow{2}{*}{$\begin{array}{c}\text { Average } \\
\text { concentration } \\
\left(\mu \mathrm{g} / \mathrm{cm}^{2}\right)\end{array}$} \\
\hline & & $\mathrm{P}$ & $\mathrm{S}$ & $\mathrm{K}$ & $\mathrm{Ca}$ & $\mathrm{Mn}$ & $\mathrm{Fe}$ & $\mathrm{Ni}$ & $\mathrm{Cu}$ & $\mathrm{Zn}$ & $\mathrm{Se}$ & \\
\hline \multicolumn{13}{|l|}{ Figure 1} \\
\hline Control & 0 & 2.24 & 8.53 & 0.57 & 3.93 & 0.06 & 0.09 & 0.02 & 0.56 & 0.22 & 0.01 & $\mathrm{~N} / \mathrm{O}$ \\
\hline Selenate & 6.3 & 1.74 & 119 & 16.8 & 132 & 0.09 & 0.32 & 0.09 & 1.11 & 0.18 & 0.02 & $0.02(0.01)$ \\
\hline Selenate & 63 & 3.61 & 58.3 & 2.54 & 30.6 & 0.04 & 0.11 & 0.03 & 0.82 & 0.23 & 14.2 & $0.75(0.50)$ \\
\hline \multicolumn{13}{|l|}{ Figure 2} \\
\hline Selenite & 0.63 & 9.60 & 94.3 & 64.9 & 61.7 & 0.29 & 0.51 & 0.28 & 1.46 & 0.35 & 301 & $32.5(24.9)$ \\
\hline Selenite & $6.3^{* *}$ & 6.56 & 395 & 17.7 & 119 & 0.23 & 2.21 & 0.13 & 0.36 & 0.50 & 41.1 & $2.10(1.45)$ \\
\hline Selenite & 6.3 & 5.64 & 9.18 & 1.33 & 4.08 & 1.33 & 19.6 & 0.64 & 16.6 & 9.00 & 14.7 & $10.6(9.68)$ \\
\hline
\end{tabular}




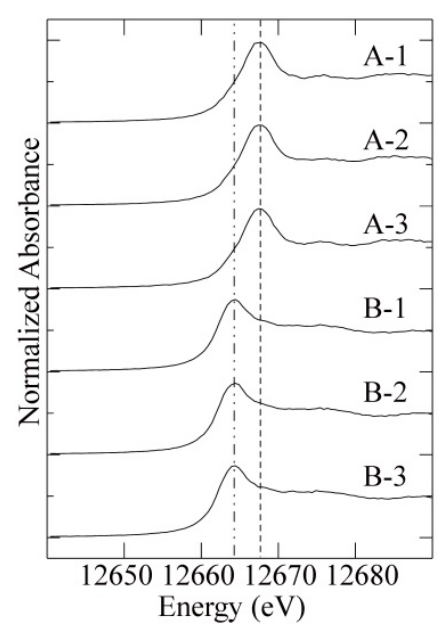

Figure S1. Selenium K near-edge spectra of selenate (A) and selenite (B) prepared as powder forms as a function of time of irradiation. Numbers after A and B indicate the order of each 120 second duration scan on the same pixel $(200 \mathrm{~nm} \times 200 \mathrm{~nm})$. Dotted and broken lines indicate the most intense peak positions of selenate and selenite. Although spectra show thickness effects, due to the use of thick particles (seen as reduced peak intensity compared with Figure S2), this should not affect possible photoreduction effects.

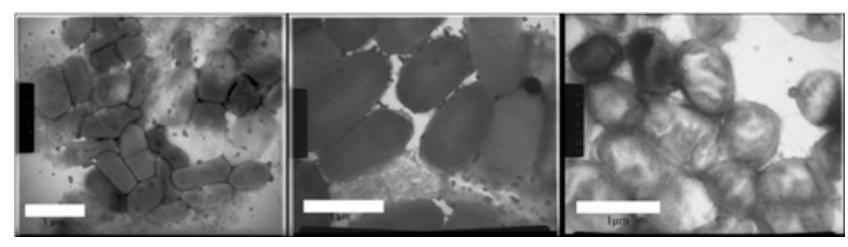

Figure S2. Transmission electron micrographs of negative stained control (no selenium; left) and 63 $\mathrm{mM}$ selenate amended biofilms incubated for 1 month (middle), and 3 months (right). Scale bars indicate $1 \mu \mathrm{m}$. 